\title{
Analysis of Character Convergence of Jiangnan Ancient Towns
}

\author{
Lei Yunyao ${ }^{1, ~ a ~}$, Zhang Qiongfang ${ }^{1, b}$ \\ ${ }^{1}$ Wuchang Shouyi University, Wuhan 430064 China \\ a910154290@qq.com, b s8789@qq.com
}

Key Words: Jiangnan Ancient Towns; Character convergence; Analysis

Abstract: This article illustrates the representation of character convergence of Jiangnan Ancient Towns. It analyzes the formation mechanism of character convergence to build the whole image of these ancient towns with Zhouzhuang as a prototype. Based on Tourism Geography Theory and Regional Linkage Theory, it puts forward the fact that the character convergence can be beneficial to building a whole tourism image and to enhancing people's awareness of ancient heritage. But some problems caused by the convergence will also be presented, such as the identical tourism development model, the backward infrastructure and the destruction of original ecology.

\section{Introduction}

With Taihu Lake as the center, the region of Jiangnan, the south of the lower reaches of the Yangtze River, is scattered all over by many historic ancient towns. These towns have a long history and deep cultural deposit. They are densely occupied and economically developed. They form a national transport network combined with inland waterway. These towns have witnessed a long-term economic prosperity in the south of the lower reaches of the Yangtze River and are now generally called "Jiangnan Ancient Towns".

Since 1980s, under the wave of reform, opening up and modernization construction, experience-based tourism and leisure tourism of these towns have achieved great development. Under the influence of "China's First Water Town" Zhouzhuang, some other similar towns like Tongli, Luzhi, Xitang, Nanxun, Wuzhen all choose to follow suit. Therefore, the regional, characteristic and cultural features of these ancient towns are becoming increasingly converged.

\section{Manifestations of character convergence}

Jiangnan Ancient Towns are located on the lacustrine plain rooted in Taihu Lake basin and Yangtze River delta. They were greatly influenced by the geographical, humanistic and cultural background of State of $\mathrm{Wu}$ (a state in ancient Spring and Autumn Period) which had an important status in Chinese cultural history. Based on the water system, these human settlements between countryside and city have been formed with a unique way of life and they have close economic activities with each other. Its picturesque image of "small bridge, flowing water, some households" is deeply rooted in the hearts of people and becomes a typical mark of local culture.

\section{Similar topographic and geomorphic conditions}

The area of Jiangnan Ancient Towns lies in the lower reaches of the Yangtze River. The south part is topographically high with mountains and hills, while the north part is topographically low with flat plains. And these ancient towns are located on plains with abundant water resources. Apart 
from abundant rainfall, many lakes and rivers are scattered throughout this area. Two main rivers, the Yangtze River and the Qiantang River, are connected to each other here through the Beijing-Hangzhou Grand Canal. Based on these topographic, geomorphic and climatic conditions, a unique natural geographical environment was formed in Jiangnan area. And people in these ancient towns chose these river network, river course, or canals as life and transportation hubs. This linked these ancient towns with the cities and the countryside together, thus constituted this special living environment with towns and streets built alongside the waterway.

\section{Closely connected historical and cultural background}

Jiangnan water towns are in the area where the cultures of State of $\mathrm{Wu}$ and State of Yue (two states in ancient Spring and Autumn Period) were formed and developed. Its cultural origins can be traced back to the first century B.C. when State of Wu was established. Its territory covered most part of the Yangtze River delta. This allowed the culture in Central China to be spread to the south of the lower reaches of the Yangtze River and to be interacted and integrated with the local culture, thus formed the $\mathrm{Wu}$ culture.

As the centre of Wu culture, this region further developed the outstanding representatives of $\mathrm{Wu}$ culture, the rice cultivating culture, arts and crafts culture, and garden culture, as the basis of the region culture. A distinct culture was formed with $\mathrm{Wu}$ culture and Yue culture integrated together. And this region was recognized as a culturally developed area as early as in Qin and Han dynasties. After Sui and Tang dynasties, the center of national economy transferred to the south of China, so the Taihu Lake basin got superior development opportunity of economic development. Therefore, the economy of Jiangnan water towns entered a stage of rapid development. And later the southward movement of the capital city of Song dynasty gave rise to further development of the economy, the progress of society and the growth of culture in this area. And this region became one of the cultural centers in Qing dynasty after more than 2000 years of emphasis on historical development of education and culture.

\section{Identical architectural style}

The natural and geographical conditions, the living and production activities of the residents in Jiangnan Ancient Towns have an inalienable relationship with water. This close relationship creates the special lasting appeal of these ancient towns with distinct spatial layout and architectural forms.

From the point of spatial pattern, the towns and streets of Jiangnan Ancient Towns are built along the rivers, and the people live along the rivers. Usually there are comprehensive architectural structures of shops with mills or residences behind or above. Most of the buildings are one or two-story tile roof houses of brick structure with courtyards, backyards and halls. The houses are built alongside the rivers with lofts and pavilions and streets nearby. The Water alley may pass through the houses. This forms a living environment harmonious with water.

\section{Formation mechanism of Character Convergence}

\section{Nature, Geography and history are the roots of Character Convergence}

The area of Jiangnan is vast in territory which is abundant with water due to crisscrossed river networks. Because of the superior natural and geographical conditions, combined with several times of population immigration from the north of China, Jiangnan region gradually developed into a 
national economic and political center since the Song dynasty.

Along with developments of local industries, such as grain, fish, fruit and cotton, Jiangnan region forms a perfect large-scale urban system with its own characteristics. As stated earlier, the people in these ancient towns build their towns and streets along the rivers, and they live along the rivers. Today, although they have different development status, some towns have been totally preserved with their original basic features, such as Zhouzhuang of Jiangsu province, Zhujiajiao of Shanghai, and Xitang of Zhejiang province, etc. The architecture, landscape, environment, historical relics, and especially the traditional atmosphere of these towns are intact, and the scenes here are still vibrant. These natural and geographical conditions and historical context are the most distinctive features of these ancient towns. And they are the essential roots of the character convergence of these towns.

\section{Following the example of Zhouzhuang model is the main means of character convergence}

Zhouzhuang was China's first ancient town to develop tourism. Accurate orientation of Zhouzhuang laid its status of "China's First Water Town". In the protection and development of Zhouzhuang, the requirements of protection planning have been strictly implemented, and great achievements have been made. The previous spatial layout and living environment have been completely preserved. And in 1995 the "ancient town protection fund" was established to link tourism economic benefits together with the protection of the ancient town. This harmonious development model has brought about mutual benefits. The tourism income provides capital for the benign development of the ancient town. This practice conforms to scientific development view and "Zhouzhuang model" was an example for other ancient towns and even other towns in the whole country to follow. The process of following suit is the main means of the character convergence.

\section{Building of a whole image is the simulative of character convergence}

At the suggestion of experts of heritage center at the United Nations, in the year of 2000, six ancient towns, Zhouzhuang, Tongli, Luzhi in Suzhou province, and Wuzhen, Nanxun, Xitang in Zhejiang province, signed a formal united application for world cultural heritage in the name of "Jiangnan Ancient Water Towns". In 2003, these six towns won the UNESCO outstanding contribution award for cultural heritage protection in the Asian-Pacific region. Henceforth, these six towns have gained great reputation.

Because the overall mode of protection and development of ancient heritage have made great achievements, Jiangnan Ancient Towns set a role model for other ancient towns in the whole country. This also influences some other ancient towns with good spontaneous protection in the south of the Yangtze River and promotes their tourism development in a more vivid whole image. Ancient towns such as Fengqiao, Guangfu, Mudu, Lili of Suzhou province, and Qiantong, Xinshi of Zhejiang province also gradually begin to attract people's attention because of this image. The overall protection and development endow these towns with the same architectural style and environmental characteristics under the same regional cultural background.

\section{Theoretical analysis of character convergence}

\section{Tourism geography theory}

Tourism geography is the study on space distribution and combination rules of tourism elements of a certain area. It studies the reasons of developing tourism and the geographical background, regional distribution and moving regularity of tourists. The classification, evaluation, protection and exploitation of tourism resources are also included. The layout and construction 
planning of a tourist area or spot, including the design of detailed tourism routes, together with the impact of tourism development on formation of a regional economy complex will also be involved.

According to the relevant theories of tourism geography, the three main elements of tourism is the subject (i.e., the tourists), the resources (i.e., the scenic spots, etc.) and tourism means or media (i.e., leisure activities, organization, transportation and reception facilities). To what degree can tourism resources meet the need of the tourists is the key to the success of the tourism development. These ancient towns, not only own the mountains, water, plants and other natural resources, but also possess constructions, gardens, folk customs and other important cultural resources as important tourism resources. Because of fully exploiting these unique characteristics, Jiangnan Ancient Towns, represented by Zhouzhuang have achieved rapid developments in tourism and other industries accordingly.

\section{Regional linkage theory}

To establish a cooperation relationship in tourism development within the scope of a certain area is the inevitable choice of tourism and economic development at a certain stage. Within a certain area, due to the geographical concentration and similar facilities, scenic spots, tourism regions will cooperate and link together to build an overall tourism brand, and enter the market with a whole image.

Under the background of regional linkage theory, Jiangnan Ancient Towns integrate the tourism resources, build a whole image and form a functional development model of "one center, two axis, and three corners". "One center" refers to the core area where Zhouzhuang and Tongli are located. "Two axis" are two intersected tourist routes connecting the core area with the three corner areas which include Guangfu Town, Mudu Town in the west angle area, Wuzhen Town, Nanxun Town, Xinshi Town in the south angle area, and Zhujia Town, Qibao Town in the east angle area.

\section{Benefits and drawbacks of character convergence}

\section{Being conducive to the whole tourism image and regional economic benefits}

The poetic and picturesque ecological space with rich water resources and distinctive architectures in Jiangnan Ancient Towns are not formed by human intervention but from the benefits of the local climate environment, geographical location and historical evolution. This precious historical and cultural heritage is beautiful treasures left over by history in the south of the lower reaches of Yangtze River, and even in the whole country of China. These towns are located in this area like pearls embedded on the land of treasure.

Under the impact of urban and modern civilization, people look forward to the return to the quiet slow rural life of original ecology for washing of the mind. As represented by Zhouzhuang, the unique style of these towns gradually gets the favor of people. Titles such as "Jiangnan Six Towns", "China's First Water Town", "Jiangnan First Garden Town" are attracting visitors at home and abroad. They flock to these places for amorous feelings of "small bridges, flowing water, some households" in Jiangnan Ancient Towns. And tourism in Jiangnan Ancient Towns becomes one big heat in the tourism industry and the successful whole tourism image has made great contributions to economic developments.

\section{Being advantageous to people's awareness of ancient heritage protection}

The protection of ancient towns and the development of tourism are of mutual promotion, and are complementary to each other. Homogenous development of Jiangnan Ancient Towns in the 
Yangtze River delta region draws the high attention of domestic and foreign professionals, because of its scale agglomeration and significant water features. There is no lack of professional workers in cultural heritage protection among them. Their concern is more conducive to the protection of a variety of cultural heritage in the region of ancient towns. Thus, more intact ancient towns of historical and cultural value may be discovered and developed. Consequently, the importance of cultural heritage of in these towns will also be known to more and more people.

With the rapid development of modern civilization and the impact of urban residents to the society, more and more people are not just concerned about protecting tangible heritages such as the architectures and spatial layout, but also pay close attention to the protection of the folk cultural heritage in these ancient towns. Folk cultural heritage is an important intangible human heritage, which stands for the spirit, essence and development level of human cultural heritage. The protection of folk culture heritage, can also let us better understand the unconscious collective core values of the local residents in the process of historical and cultural development. Only through the dual protection of tangible and intangible heritage sites, can we protect the historical and cultural heritages and the ancient towns totally.

\section{Identical Tourism development model}

First of all, tourism models of Jiangnan Ancient Town are limited in half- day or one -day tours, mainly restricted to the water towns, due to traditional economic production mode and the typical regional culture. The space scale is small, and the pace of life is slow than modern life; Secondly, tourism projects are almost the same, no more than wandering about the streets, walking in some old houses or several gardens, visiting the towns by cruise, or spending the night in the traditional dwellings after a big meal, etc. Finally, there is a severe resemblance of souvenirs and snacks, such as ethnic costumes, wood carving, embroidery, bean curd with odor, and so on. It seems almost all Jiangnan water towns in tour are the same. No one has any bright spot. The visitors are easy to get bored. Especially in the tourist season, some famous tourism scenic spots are overloaded and visitors often feel deeply disappointed because they are unable to look around for long in the overcrowded places. Therefore, they don't have a deep impression and they may never come again. And this is not beneficial for the long-term development of tourism in these towns.

\section{Discordant infrastructure with tourist capacity}

The original ecological layout of Jiangnan Water Towns is mainly focused on the purpose of dwelling and cottage economy. And its full-bodied amorous feeling of water production and living, is the biggest attraction to tourists at home and abroad. However after entering a stage of development and protection going hand in hand, a growing number of visitors flock to the so-called pleasant space, which was originally residential places with limited capacity. And out of concept for the protection of the ecological environment, the existing service facilities such as traffic space, business services, recreation experience, etc. can't match with modern requirements of tourists. According to previous planning, tourist arrivals of Zhouzhuang should be no more than 600000 every year, and capacity of other towns can be analogized according to this. However, even with the increase of ticket price, more than 2 million tourists come here for visit each year. But many return home with an unpleasant feeling, because they cannot really feel the distinctive flavor of Jiangnan Ancient Towns. 


\section{Ecological destruction caused by overexploitation}

Under the background of the rapid exploitation of tourism, for the sake of profitable purpose, local residents give up farm production and engage in trading. They open shops and many local residents rent their own underlying residence to outsiders. This behavior not only destroys the original architectures but also influence the local ecological environment, social structure and the folk culture. The hollowing-out development method exacerbates tourism commerce to be over-commercialized. Original and adjacent water system linked to the underlying residential living space is filled with commercial facilities, which also has a bad influence on tourism environment of these ancient towns.

\section{Conclusion}

Under the background of rich water resources and a long history, Jiangnan Ancient Towns have built a whole image of consistent architectural style, similar spatial layout and identical construction techniques after nearly 30 years of development. Building of a whole image with Zhouzhuang mode as a prototype is the path to character convergence. It is also the direct embodiment of Tourism Geography Theory and Regional Linkage Theory in the ancient town tourism. Character convergence of Jiangnan Ancient Towns is advantageous to the ancient town tourism image as a whole and people's awareness of ancient heritage protention at the same time, but it also leads to a series of problems such as the identical development model, infrastructure lag and ecological destruction, etc.

\section{References}

[1]Wen Jiangang. The Image of Small Towns and Environmental Art Design [M]. Nanjing: Southeast university press, 2001

[2]Peng Jun, Zhao Shiyong. Jiangnan Ancient Towns [M]. Tianjin: Tianjin University Press, 2009. [3]Ruan Yisan, Li Zhen, Lin Lin. Jiangnan Ancient Towns: The Protection of Historical Buildings and Historical Environment [M]. Shanghai: Shanghai People's Fine Arts Publishing House, 2010. [4]Li Zhiming. Multiple Reading and Thinking of Jiangnan Ancient Town Space [J]. New Architecture, 2005 (05):68-72.

[5]Ruan Yisan, Shao Yong, Lin Lin. The characteristics, value and protection of jiangnan water towns [J]. Tourism development research, 2008 (11):120-121. 